\title{
RETRACTED ARTICLE: Histologic parameters for detecting multiple blood meals in Aedes albopictus (Skuse) (Diptera: Culicidae) during a single gonotrophic cycle
}

\author{
Abeer S. Yamany ${ }^{1}$ - Fatma K. Adham ${ }^{2} \cdot$ Heinz Mehlhorn ${ }^{3}$
}

Received: 25 August 2016/Accepted: 11 December 2016/Published online: 27 December 2016

(C) Springer-Verlag Berlin Heidelberg 2016

The editors are retracting the article by Yamany et al (2016) because portions of text in the article are unoriginal. Major overlaps were detected with Scott et al (1993).

Heinz Mehlhorn agrees to this retraction. Abeer S. Yamany and Fatma K. Adham have not responded to correspondence about this retraction.
References:

Scott, T. W., G. G. Clark, L. H. Lorenz, P. H. Amerasinghe, P. Reiter, and J. D. Edman (1993). Detection of Multiple Blood Feeding in Aedes aegypti (Diptera: Culicidae) During a Single Gonotrophic Cycle Using a Histologic Technique, Journal of Medical Entomology

Yamany, A.S., Adham, F.K. \& Mehlhorn, H. (2016). Histologic parameters for detecting multiple blood meals in Aedes albopictus (Skuse) (Diptera: Culicidae) during a single gonotrophic cycle. Parasitol Res https://doi.org/10.1007 /s00436-016-5348-z

\footnotetext{
Abeer S. Yamany

emarewan@yahoo.com

1 Zoology Department, Faculty of Science, Zagazig University, Zagazig, Egypt

2 Entomology Department, Faculty of Science, Cairo University, Giza, Egypt

3 Zoology, Cell Biology and Parasitology Institute, Heinrich-Heine University, Duesseldorf, Germany
} 